\title{
CONTROLE PROPORCIONAL INTEGRAL DIGITAL APLICADO EM VÁLVULA BORBOLETA AUTOMOTIVA
}

\author{
Rodrigo Peralta Moraes Ruiz, Thiago Ragozo Contim e Armando Antonio Maria Laganá \\ Escola Politécnica da Universidade de São Paulo
}

E-mails: rodrigoperaltamoraes@hotmail.com,thiago@contim.eng.br, lagana@1si.usp.br

\section{RESUMO}

Atualmente, o aumento da necessidade de economia e rendimento em motores de combustão interna têm sido os principais alvos das grandes montadoras e sistemistas da área automotiva. No gerenciamento eletrônico de motores, o controle preciso do corpo de borboleta tem fundamental importância para os objetivos citados, uma vez que a mesma é responsável por permitir a passagem de ar para o motor. Neste artigo, foi projetado um controlador para uma válvula borboleta automotiva a partir de um modelo matemático levantado por meio de identificação não paramétrica da mesma, com o intuito final de ser aplicado em uma unidade eletrônica de gerenciamento flex que se encontra em estado de desenvolvimento. Os resultados apresentados denotam que um controle a partir da modelagem citada, isto é , uma identificação "Caixa Preta", pode ser de grande valia quando se necessita obter o comportamento dinâmico do sistema sem se ater aos detalhes físicos da válvula, tal estratégia economiza tempo e apresenta resultados satisfatórios.

\section{INTRODUÇÃO}

Ao longo dos últimos anos, a eletrônica vem gradativamente tomando espaço dentro dos veículos, mais especificamente no tocante ao gerenciamento eletrônico de motores, tanto de passeio quanto de competição e até mesmo de carga . O papel do gerenciamento eletrônico no contexto de desenvolvimento e aplicação de controle nos motores à combustão interna é, sem dúvida, de extrema importância para atingir um equilíbrio satisfatório entre potência, durabilidade e economia [7].

A partir do controle da válvula borboleta, é possível administrar a entrada de ar dentro do cilindro do motor. Um motor de corrente contínua, localizado no corpo de borboleta, é responsável por acionar engrenagens que por sua vez estão conectadas ao "prato" da válvula. Dessa forma, a abertura e o fechamento da válvula são controlados por meio da tensão aplicada aos terminais do motor.

Dentre as diversas técnicas de controle clássico, o controle proporcional, integral e derivativo (PID) é um dos mais utilizados, devido à sua abrangente aplicação. Este artigo trata do desenvolvimento de um controle proporcional, integral (PI), utilizando a teoria de controle digital para possibilitar sua implementação em um hardware microcontrolado, posteriormente, ser incorporado à unidade de gerenciamento flex [2]-[4]. 


\section{INJEÇÃO ELETRÔNICA DE COMBUSTÍVEL}

1.1 O sistema e seus elementos

O sistema de injeção eletrônica de combustível é responsável por controlar da maneira mais precisa possível as variáveis de tempo de injeção, momento de ignição e massa de ar admitida, de modo que o motor atue dentro de especificações de potência , economia e emissões de poluentes [7].

De maneira geral, a unidade de controle do motor, ou como comumente é intitulada "Engine Control Unit" (ECU), tenta manter proporção ar/combustível dentro da relação estequiométrica. Para isso, é necessário controlar a quantidade de ar a ser admitida pelo motor. A ECU recebe o sinal do sensor de combustível (Sonda Lambda) e, a partir do mesmo, efetua os cálculos de tempo de injeção. Consequentemente, haverá um valor de massa de ar correspondente a fim de que a mistura atinja a proporção mais próxima possível do ideal [5,7]. O controle preciso de posição da válvula borboleta possibilitará o gerenciamento da admissão de ar no motor à combustão interna, levando-o a trabalhar dentro das especificações requisitadas [8].

\subsection{Válvula Borboleta}

Dentre as grandes mudanças ocorridas nos últimos anos nos componentes de controle em motores automotivos, vale destacar a válvula borboleta eletrônica.

Antes do conceito de controle eletrônico da válvula borboleta, a massa de ar era controlada de acordo com a demanda do condutor, de maneira que o prato da válvula era diretamente conectado ao pedal acelerador, por meio de um cabo de aço. Ao se pisar no acelerador, o cabo de aço acionava o prato da válvula, promovendo sua abertura e possibilitando a passagem de ar. Todavia, com essa configuração, muitas variáveis e condições internas e externas eram ignoradas. Sendo assim, a eficiência da combustão era prejudicada e, de modo geral, o desempenho do motor também [6].

A fim de suplantar as deficiências causadas pelo antigo sistema, um módulo de controle foi incorporado à borboleta, de forma a determinar o ângulo que melhor contribua com as condições imediatas do motor. 
A figura 1 mostra um diagrama do sistema de controle eletrônico da válvula.

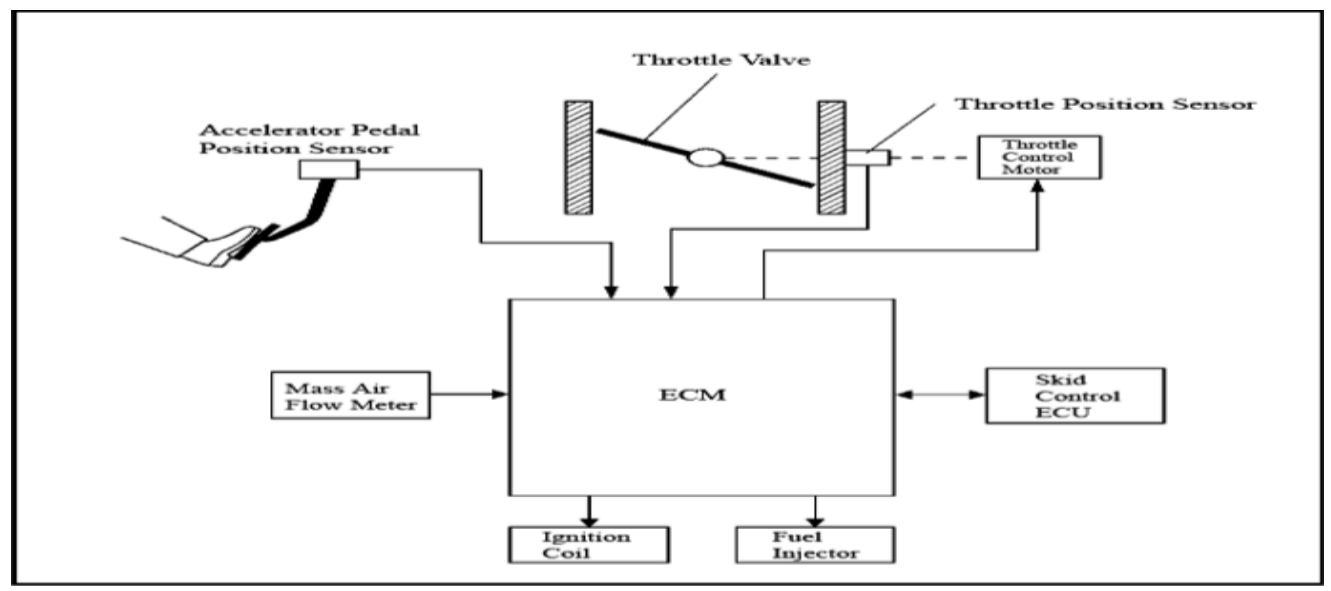

Figura 1- ECU [6].

A válvula é composta por um motor de corrente contínua, que por sua vez está diretamente conectado a engrenagens, também há neste modelo de válvula, duas molas, uma é responsável pela abertura e outra pelo fechamento do prato. Caso não haja o acionamento do motor, a válvula permanece "relaxada" em uma posição denominada "Limp Home” que, segundo Thamires (2015,p.30): “[..]Limp Home é o ângulo de abertura da válvula borboleta determinado pela mola de retorno acoplada ao corpo da válvula para que o veículo possua o mínimo de entrada de ar necessária para se direcionar a um local seguro em caso de pane[..]".

Uma vez aplicada uma tensão aos terminais do motor, o deslocamento de seu rotor vence a força das molas, movimentando dessa maneira o prato da válvula.

Neste projeto, a válvula utilizada pertence ao veículo "Volkswagen Polo 1.6 Flex" ano 2006.A figura 2 mostra a foto da válvula borboleta utilizada.

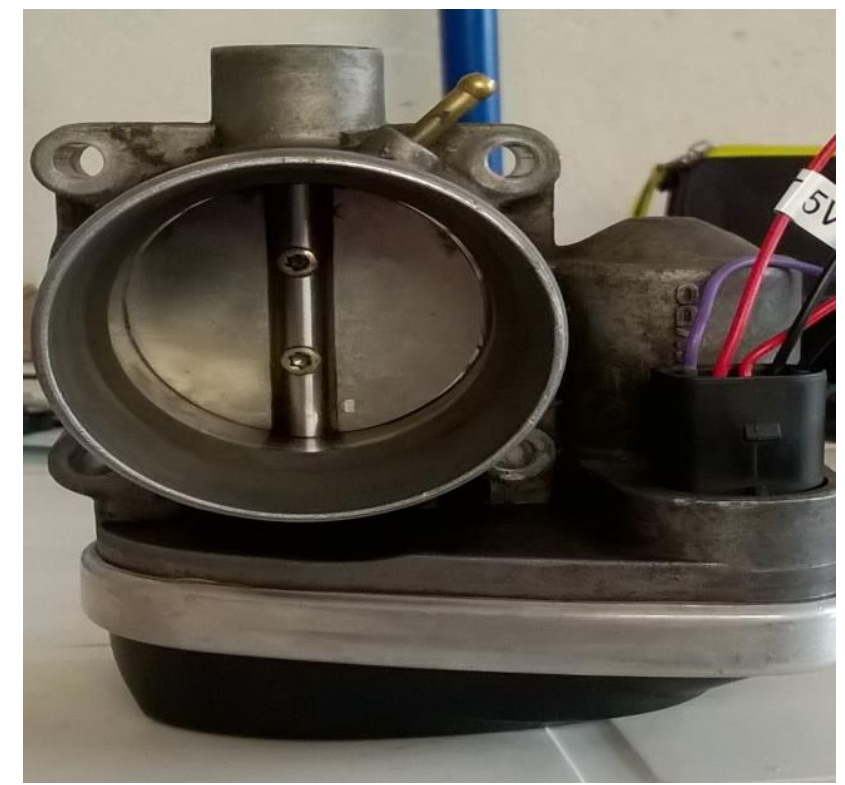

Figura 2- Válvula Borboleta. 


\subsection{O controle}

As questões atreladas ao controle da válvula borboleta são frequentemente discutidas e desenvolvidas na literatura devido à sua importância em aplicações industriais.

Projetos de sistemas de controle para a válvula borboleta são sem dúvida cada vez mais crescente no contexto de tecnologias automotivas. O controle de posição, isto é, o ângulo do prato da borboleta em relação à sua posição em repouso, permite administrar quantidade de ar admitida pelo motor. O fluxo de ar, por sua vez, controlará diretamente o torque de saída do motor e, consequentemente, sua velocidade, de acordo com a demanda [6].

O controle utilizado neste projeto é denominado como "Proporcional Integral" (PI), no controle proporcional de uma planta em que a função de transferência é configurada originalmente sem um integrador, existe um erro estacionário na resposta para entrada em degrau. Ao se adicionar o controle integral, o sinal de controle atua em função da área sob a curva de erro atuante até aquele momento. Portanto, o controle proporcional tende a estabilizar o sistema, enquanto a ação de controle integral leva o sistema a ter erro estacionário nulo, ou bastante reduzido para vários sinais de entrada $[3,4]$.

O motor de corrente contínua, responsável pelo acionamento do prato da válvula borboleta, trabalha com uma tensão máxima de 12 Volts. De forma similar a um servomecanismo, o motor mantém a válvula em uma determinada posição para um valor de tensão específico.

\section{CARACTERÍSTICAS DO HARDWARE UTILIZADO}

\subsection{Microcontrolador PIC18F4550}

O sistema foi implementado em um microcontrolador PIC18F4550. Esse dispositivo incorpora todos os recursos de comunicação Universal Serial Bus (USB) condizentes com as especificações da configuração "USB 2.0". O módulo suporta tanto comunicações de baixa quanto de alta velocidade, e também incorpora no próprio chip transceptores e reguladores de 3.3V [9].

O presente dispositivo possibilita diferentes maneiras de configurar a frequência de oscilação em comparação com os outros dispositivos da família "PIC18F". A fim de acomodar os requisitos de operação da comunicação USB, o PIC18F4550 inclui uma nova ramificação de clock para prover $48 \mathrm{MHz}$ à operação USB de alta velocidade, de modo que um sistema adicional de prescalers e postscalers foi incluído para comportar uma larga escala de frequências de oscilação. Sendo assim, o dispositivo permite ao projetista configurar determinados registradores, a fim de obter as frequências desejadas para o microcontrolador trabalhar com a comunicação USB [9]. Dentre os diversos arranjos possíveis para a configuração da frequência de oscilação, o presente projeto teve por opção utilizar o circuito de Phased Locked Loop (PLL), que é fornecido especificamente para aplicações com a comunicação USB utilizando cristais de baixa frequência. 
O modo PLL é projetado para produzir um valor fixo de 96MHZ de oscilação para uma entrada de referência de $4 \mathrm{MHZ}$. A saída pode então ser dividida e usada, tanto para fornecer a frequência da comunicação USB, quanto para o microcontrolador. Devido ao fato do PLL ter valores fixos de frequência, tanto na saída quanto na entrada, existem oito opções de prescaler para configurar a frequência do PLL, há também uma opção de postscaler para fornecer ao microcontrolador a frequência desejada. Dessa forma, o circuito de Phased Locked Loop permite que o microcontrolador e a comunicação USB usufruam da mesma fonte de oscilação e ainda operem com diferentes velocidades [9].

O kit didático utilizado no projeto é programado/gravado diretamente do computador por meio de um cabo "USB 2.0". A frequência do oscilador da placa de circuito impresso é de $20 \mathrm{MHZ}$ e as configurações necessárias foram efetuadas para que a comunicação USB trabalhasse com 48MHZ. A figura 3 mostra a foto do kit utilizado.

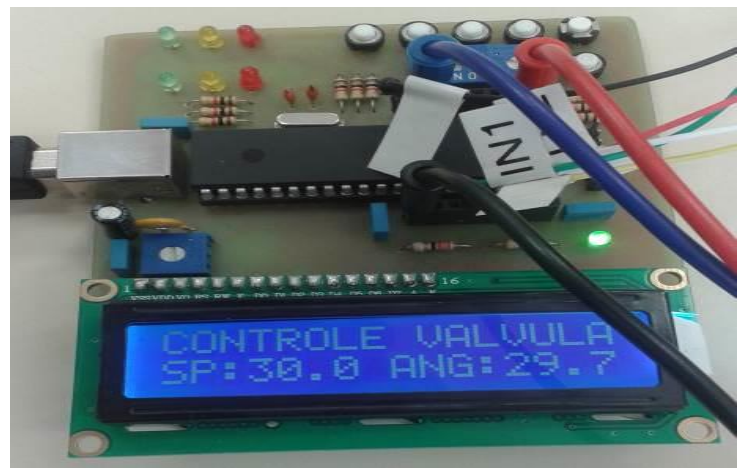

Figura 3- Kit de Desenvolvimento

\subsection{Sinal PWM}

Como já citado neste artigo, a posição do prato da borboleta é controlada por um motor de corrente contínua alimentado com $12 \mathrm{~V}$. Variando-se a tensão no motor, desloca-se de forma proporcional o prato da válvula.

O microcontrolador possui um módulo interno que gera um sinal modulado por largura de pulso, popularmente conhecido como "Pulse Width Modulation" (PWM). Pode-se definir um sinal PWM como sendo um sinal de frequência fixa e largura de pulso variável. A largura de pulso, que é denominada como "Ciclo Ativo" ou "Duty Cicle", é a parte responsável por manter o sinal em nível lógico alto. Embora o sinal PWM seja categorizado como digital, há um valor médio associado a ele, sendo que a variação do ciclo ativo resulta na variação do valor médio do sinal [2]. A figura 4 ilustra as características de um sinal PWM.

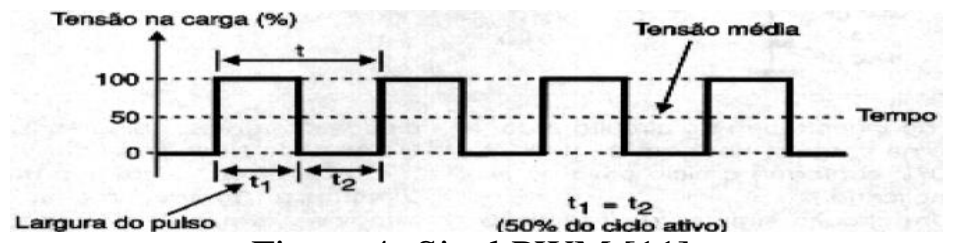

Figura 4- Sinal PWM [11]. 
A posição da válvula borboleta neste projeto será controlada por meio de um sinal PWM gerado por um módulo interno no microcontrolador já concebido para essa finalidade. O módulo Capture, Compare, PWM (CCP) do PIC18F4550 pode ser configurado para fornecer um sinal com frequência fixa e largura de pulso variável. Dessa maneira, o sinal de controle neste projeto será um valor que oscila entre $0 \mathrm{e}$ $100 \%$, sendo esse valor diretamente relacionado com o duty cicle do sinal PWM.

\subsection{Driver de Potência}

O chip escolhido para fazer o chaveamento de potência, ou seja, a interface entre a saída do microcontrolador e a entrada do motor da válvula, foi o MC33186. Esse circuito integrado é fabricado pela Freescale e é apropriado e certificado para aplicações automotivas. O chip é composto por uma "ponte $\mathrm{H}$ " que possibilita o controle bidirecional do motor da válvula borboleta eletrônica [10]. A figura 5 mostra o esquema elétrico do circuito integrado.

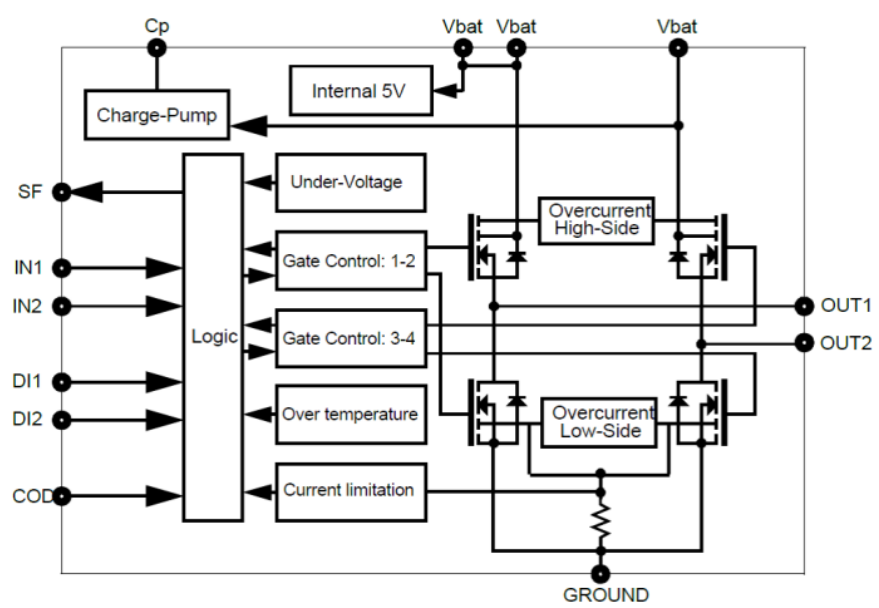

Figura 5- Diagrama Elétrico do driver [10].

A seguir são apresentadas algumas características do driver utilizado:

- Tensão de operação de 5 Volts até 28 Volts;

- Proteção contra transientes de até 40 Volts;

- Resistência de Canal do MOSFET quando ligado de $150 \mathrm{~m} \Omega$ na temperatura de $25^{\circ} \mathrm{C}$

- $\quad$ Corrente contínua de operação menor ou igual a 5A;

- $\quad$ Proteção contra curto-circuito de 8A;

- $\quad$ Frequência de operação de até $20 \mathrm{KHz}$;

- Proteção de aquecimento excessivo de temperatura;

- $\quad$ Entradas de controle compatíveis com níveis TTL/CMOS; 


\section{3- DESENVOLVIMENTO E RESULTADOS EXPERIMENTAIS}

\subsection{O Modelo da Planta.}

Para obter o modelo da planta foi realizada uma identificação não paramétrica em malha aberta, aproximando-se um modelo de primeira ordem pelo método de Hägglund para a resposta ao degrau [1]. Uma interface de comunicação serial padrão RS232 foi utilizada para enviar os dados ao computador no formato ".csv", de maneira que os dados pudessem ser manipulados via Excel e também por meio do software de simulação MATLAB®.

Um sinal do tipo degrau foi aplicado na entrada da planta a fim de obter a resposta da mesma. A resposta ao degrau é um procedimento adequado para caracterizar, de forma preliminar a dinâmica de um processo por meio de interpretações gráficas [1]. Devido a ao fato da válvula borboleta possuir uma dinâmica muito abrupta, a amplitude do degrau de entrada teve de ser baixa para que fosse possível observar o comportamento da saída de forma a aproximar um modelo de primeira ordem para tal resposta. É válido lembrar que o sinal de controle do presente projeto é do tipo PWM, sendo assim, a planta foi submetida a um sinal com ciclo ativo de $12.35 \%$ (o que corresponde a um valor médio de aproximadamente 1.5 Volts). O tempo de amostragem estabelecido para a identificação do sistema foi de 10 milissegundos, portanto, a cada intervalo de amostragem o sistema envia ao computador os dados de tempo, ângulo da válvula e porcentagem da saída do sinal PWM. A válvula possui um sensor de posição denominado "Throttle Position Sensor" (TPS). O sensor emite uma tensão linearmente proporcional ao ângulo da válvula, sendo que a tensão no sensor varia de $0 \mathrm{~V}$ a $5 \mathrm{~V}$ e o ângulo da válvula varia de $0^{\circ}$ a $90^{\circ}$. Todavia, a válvula utilizada no presente projeto tem a sua posição de repouso em $5.9^{\circ}$. Foi estabelecida a estratégia de levantar inicialmente um modelo para a abertura da válvula e, ficando o controle de descida atribuído a outro controlador independente, que será abordado ademais neste projeto. A figura 6 mostra a resposta da válvula para um degrau de $12.35 \%$ na entrada.

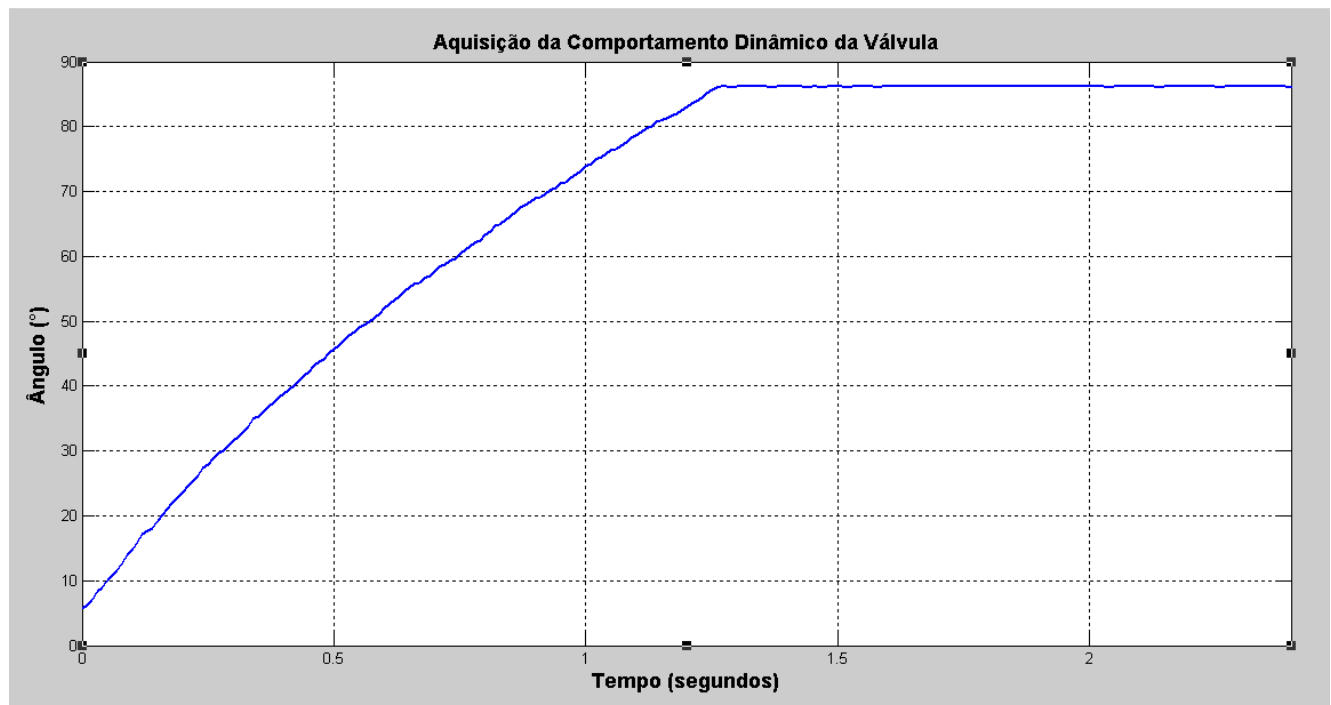

Figura 6- Resposta da válvula para entrada "Degrau". 
Um modelo da dinâmica de um processo, comumente utilizado para aproximações de primeira ordem é mostrado em (1):

$$
G(s)=\frac{K}{\tau s+1} e^{-\theta s}
$$

Esse modelo é configurado pelo ganho estático $\mathrm{K}$, pela constante de tempo $\tau$ e pelo atraso de transporte $\theta$ [1]. A partir da resposta ao degrau coletada, os parâmetros foram estimados de modo que K é obtido dividindo-se o valor final da saída pelo valor da entrada, a unidade de saída do presente projeto é o ângulo da válvula em graus, e a entrada é um valor que varia de 0 a $100 \%$, correspondente ao ciclo ativo do sinal PWM. Sendo assim:

$$
K=\frac{86.3^{\circ}}{12.35 \%} \cong 7
$$

$\tau$ é o tempo em segundos que o sistema leva para atingir $63.2 \%$ de seu valor final [4]. Como na amostragem não foi possível obter uma valor de amostra que correspondesse exatamente a um valor de $63.2 \%$, a constante de tempo foi extraída a partir da amplitude mais próxima possível do valor de $63.2 \%$ :

$$
\tau=0.64 \mathrm{~s}
$$

O sistema não possui atraso de transporte, portanto esse quesito será desconsiderado. Com os parâmetros estimados obteve-se a seguinte função de transferência em malha aberta:

$$
G(s)=\frac{7}{0.64 s+1}
$$

Foi desenvolvido um script no software de simulação matemática MATLAB® para calcular o percentual de compatibilidade do modelo levantado com a curva original. A figura 7 mostra o resultado da primeira comparação:

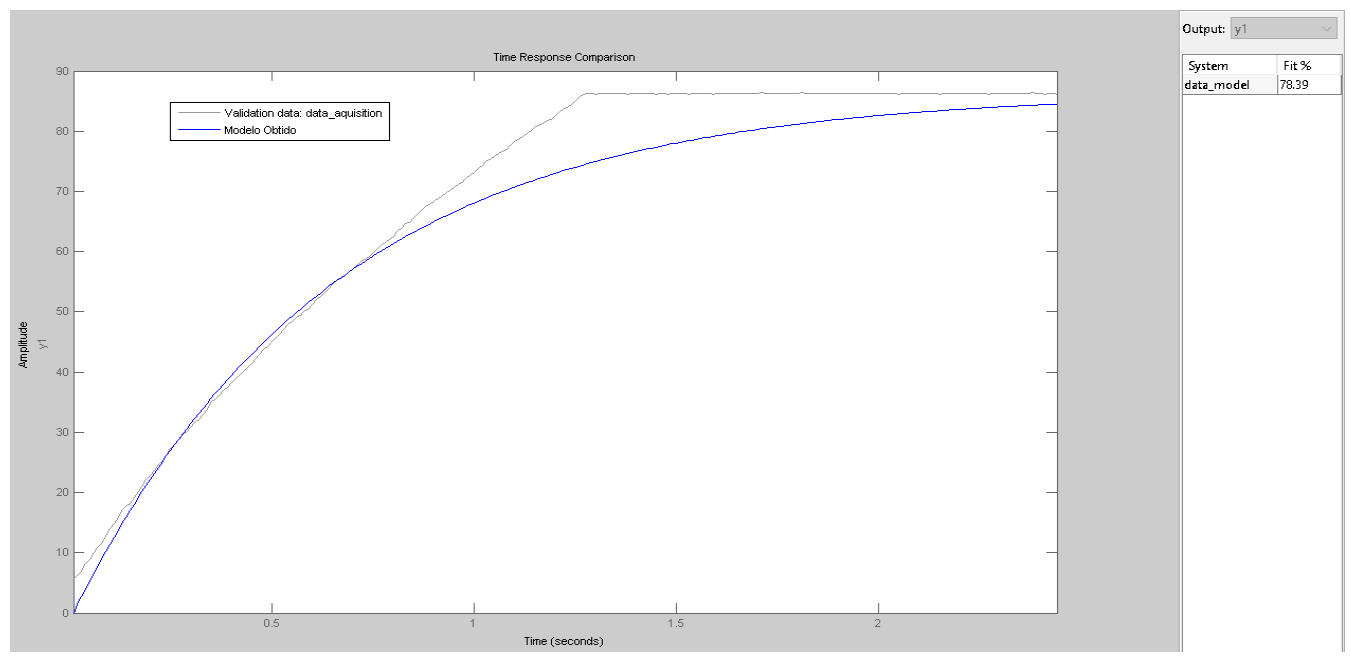

Figura 7- Comparação do modelo obtido com a resposta da planta. 
Como é possível observar, o percentual de compatibilidade é de $78.39 \%$, no intuito de aumentar este percentual e consequentemente melhorar a fidelidade do modelo em relação à curva original, o ganho do modelo foi reajustado para um valor de "7.5", obtendo-se a seguinte função de transferência:

$$
\frac{7.5}{0.64 s+1}
$$

A figura 8 mostra o resultado da segunda comparação com o ganho reajustado:

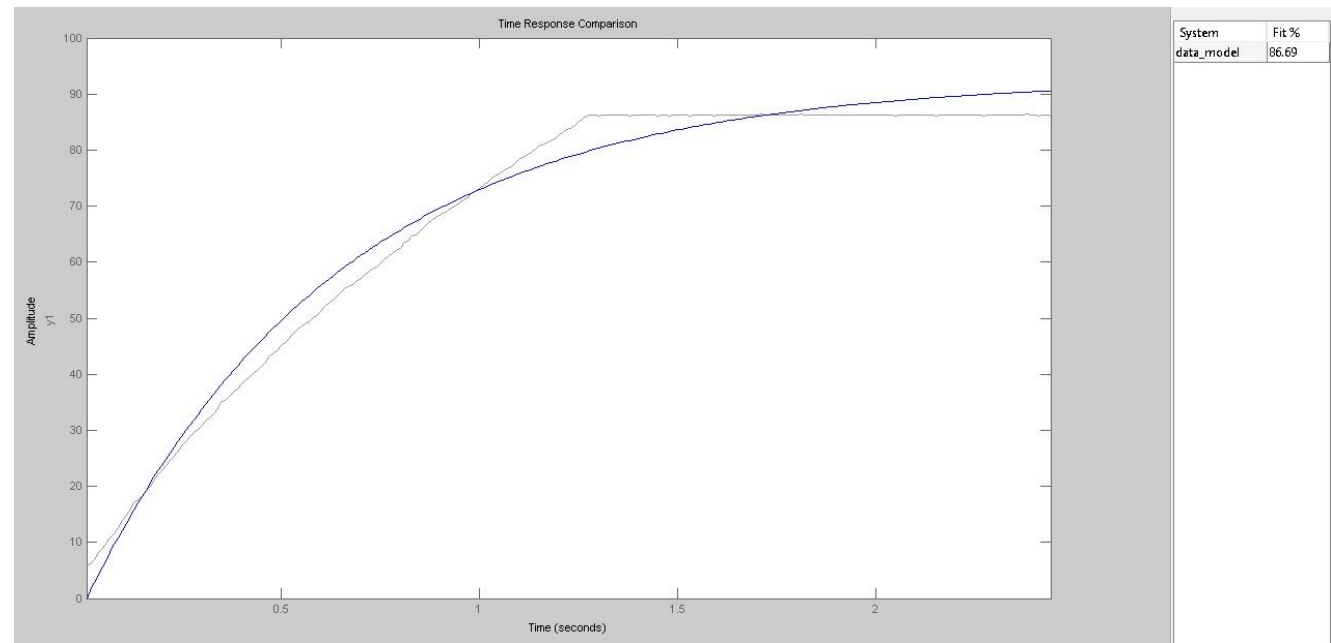

Figura 8- Comparação da resposta do modelo reajustado com a resposta da planta.

Como o gráfico denota , o valor de compatibilidade aumentou para $86.69 \%$, foi optada a utilização do modelo de (5) como modelo base para a síntese do controlador.

3.2 Projeto do Controlador e Simulação no MATLAB®.

Inicialmente foi projetado um controlador a partir dos seguintes requisitos de desempenho:

- $\quad \zeta=0.9 \Rightarrow M p=0.15 \%$

- $\quad$ Tempo de subida de 200 milissegundos.

Esses requisitos foram alterados posteriormente para atender às demandas do projeto.

O projeto foi realizado pelo lugar geométrico das raízes. A partir dos requisitos de desempenho, obtém-se os seguintes polos desejados em malha fechada:

$$
s_{0,1}=\sigma \pm \mathrm{j} \omega=-27.77 \pm \mathrm{j} 13.45
$$

O controlador será implementado como sendo proporcional, integral, como mostrado em (7) 


$$
C(s)=K p+\frac{K i}{s}
$$

Desenvolvendo a equação obtemos o controlador na forma de um compensador de atraso de fase, conforme a equação (8).

$$
C(s)=K \frac{(s+a)}{s}
$$

O polo do controlador foi alocado na origem do plano "s" adicionando dessa maneira um fator integrador ao sistema, o zero do controlador foi obtido como sendo um décimo da parte real do polo desejado, o ganho do controlador foi calculado pela restrição de módulo.

- Polo $=0$.

- Zero $=\sigma \frac{1}{10}=-2.77$.

- $\mathrm{Ganho}=\mathrm{K}=\frac{1}{\left|C\left(s_{0}\right)\right|\left|G\left(s_{0}\right)\right|}=2.57$

A equação (9) mostra o controlador projetado no plano "s".

$$
C(s)=2.57 \frac{(s+2.77)}{s}
$$

A figura 9 mostra a simulação da resposta da planta para o controlador contínuo.

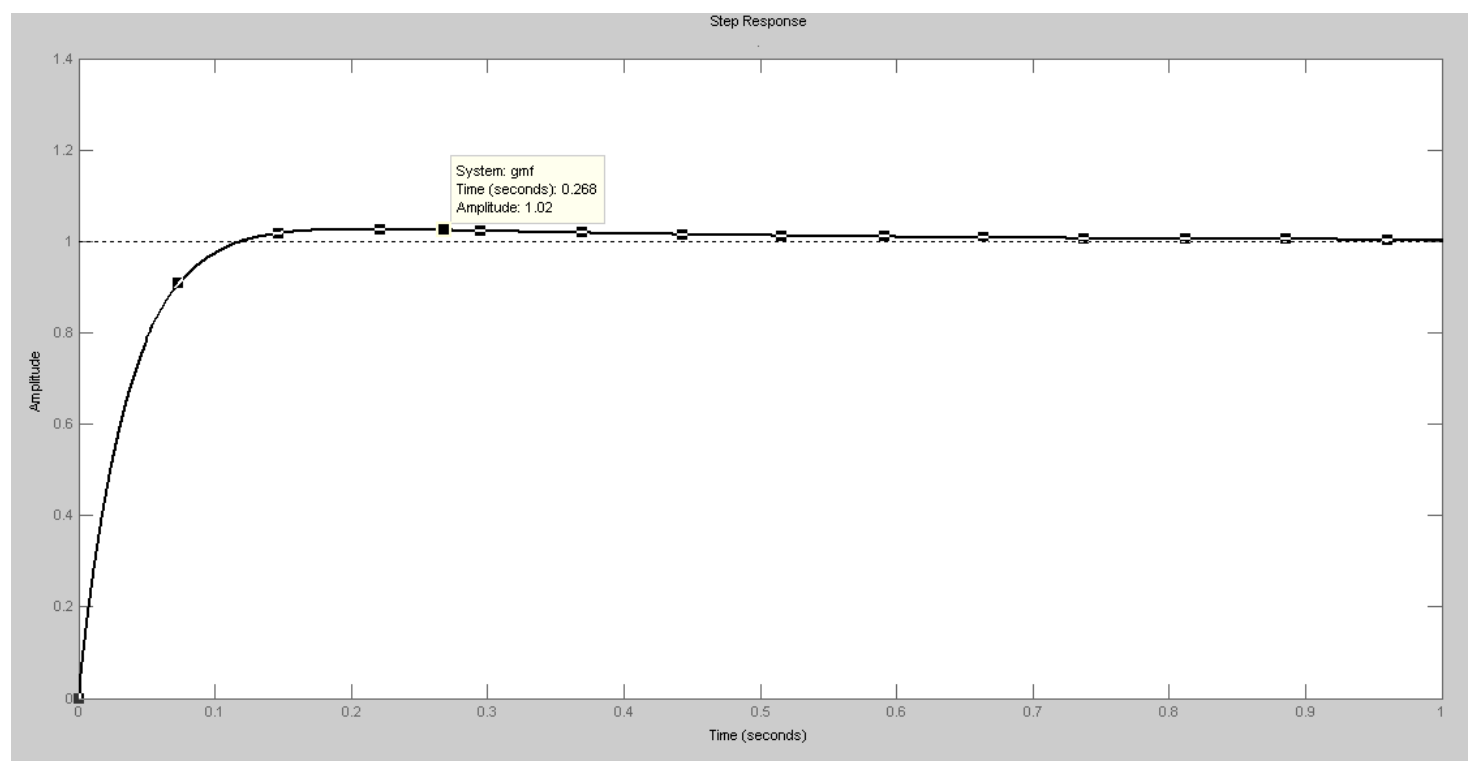

Figura 9- Simulação da planta com o controlador contínuo 
O controlador foi discretizado pelo método de "Tustin", pois tal método é o que melhor aproxima a parcela integrativa [3]. O período de amostragem utilizado foi de 10 milissegundos, valor sessenta e quatro vezes menor do que a constante de tempo do sistema. O controlador é mostrado em (10).

$$
C(z)=2.53 \frac{(z-0.9727)}{z-1}
$$

A figura 10 mostra a simulação da resposta da planta com o controlador discretizado.

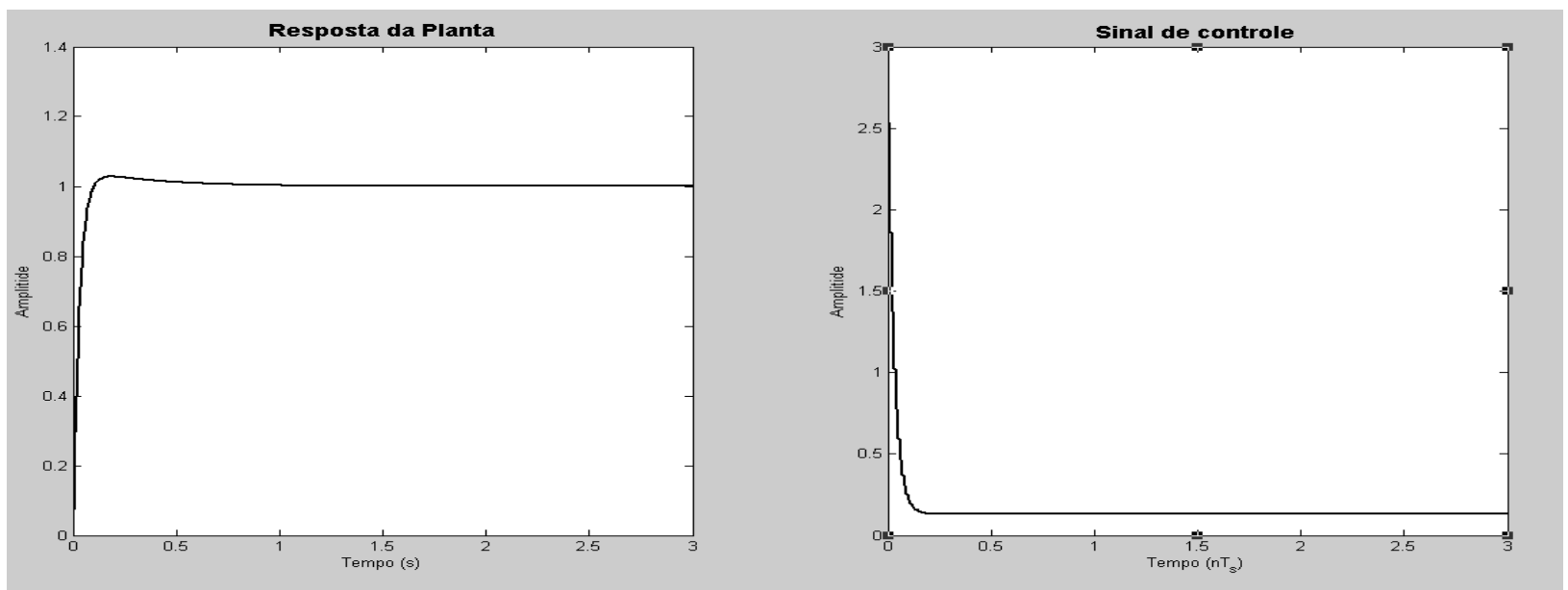

Figura 10- Simulação da planta com o controlador discreto

\subsection{Implementação no Hardware Microcontrolado}

A figura 11 mostra o diagrama de blocos do sistema de controle implementado no microcontrolador PIC18F4550. Os blocos sinalizados em laranja fazem parte da própria arquitetura do microcontrolador. A partir do valor de setpoint, o algoritmo calcula o erro e atua no sinal PWM, variando seu ciclo ativo. O sinal passa pelo driver de potência para ser amplificado, possibilitando o acionamento do motor. O sensor de posição da válvula fornece uma tensão que varia de $0 \mathrm{~V}$ a $5 \mathrm{~V}$, correspondendo linearmente ao ângulo da borboleta. A tensão passa pelo conversor Analógico/Digital do mcirocontrolador para que os dados possam ser processados. O controlador foi implementado no PIC18F4550 na forma de equação de diferenças. Inicialmente o controlador foi utilizado com a forma e os valores apresentados em (10), isto é, sem realizar nenhum tipo de ajuste. $\mathrm{O}$ valor de $50^{\circ}$ é estabelecido como setpoint para a aquisição inicial.

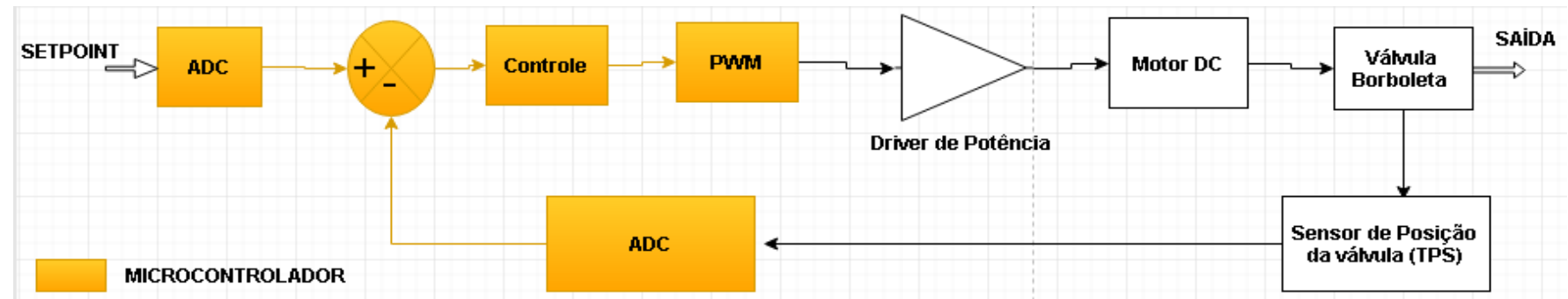

Figura 11- Diagrama de blocos do sistema de controle. 
Ao se discretizar o controlador , é possível obter a equação de diferenças do mesmo e com isso, implementar a equação no firmware de controle, em (11) é mostrada a equação de diferenças:

$$
u[n]=2.53 e[n]-2.46 e[n-1]+u[n-1]
$$

Aonde "e[n]" é o erro da enésima amostra e "u[n]" é a atuação de controle da enésima amostra.

A figura 12 mostra a resposta da planta com o controlador projetado para um setpoint de $50^{\circ}$.
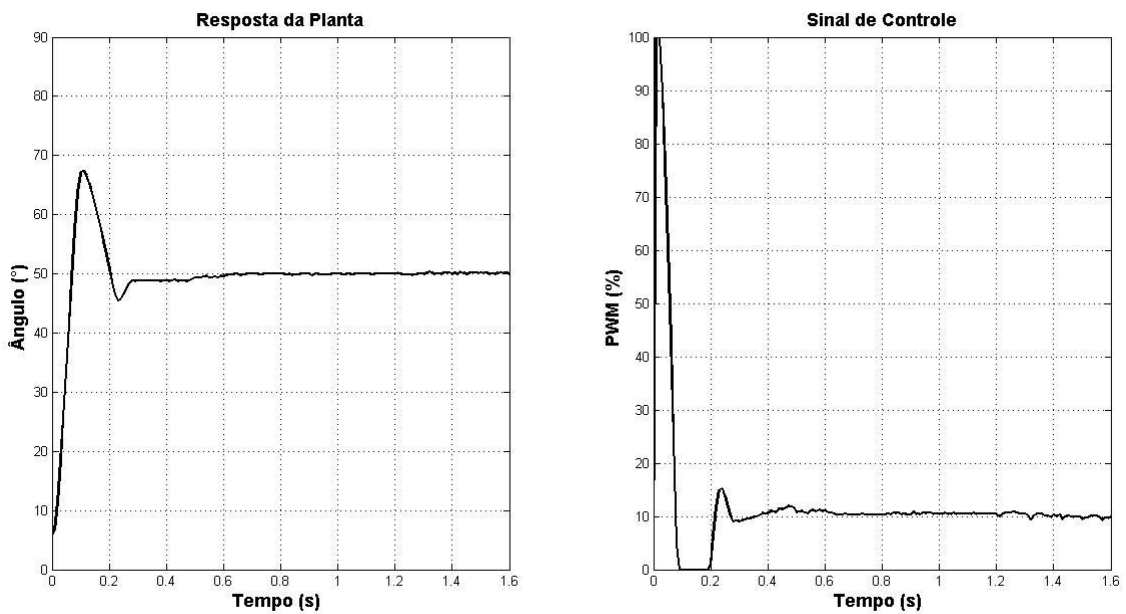

Figura 12- Primeira resposta da planta.

Como é possível observar, o sistema apresenta um tempo de subida de aproximadamente 70 milissegundos, entretanto, o overshoot ultrapassa o valor de $30 \%$ para o setpoint estabelecido, sendo assim, é necessário realizar alguns ajustes no compensador, o primeiro ajuste foi a alocação o zero do controlador mais próximo da origem no plano " $\mathrm{z}$ " em 0.9827 , com isso um polo mais lento é adicionado em malha fechada, diminuindo consequentemente o sobressinal. A resposta para o controlador ajustado é mostrada na figura 13.
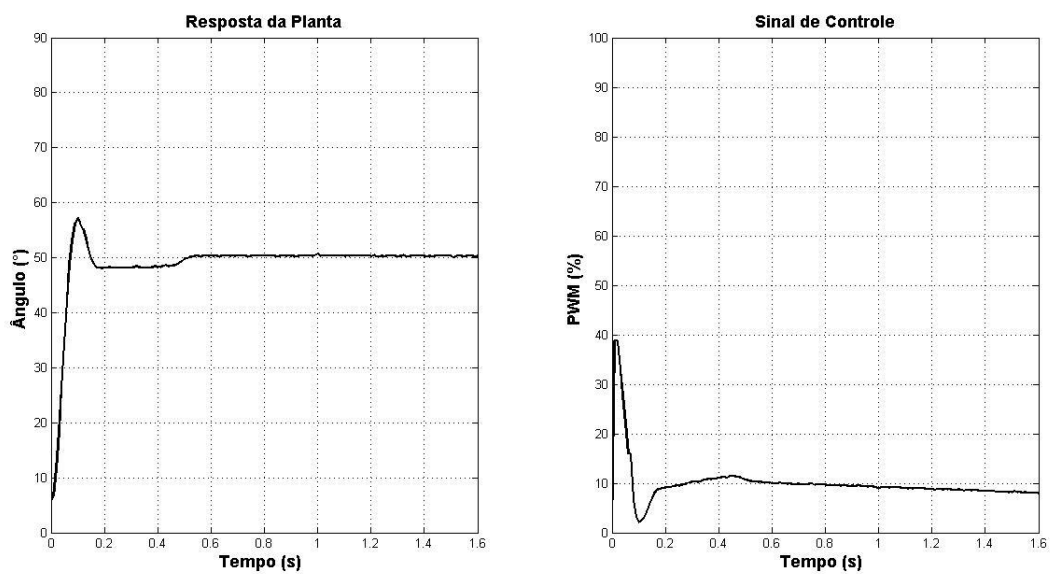

Figura 13- Resposta do sistema com o controlador ajustado. 
É notória a melhora da resposta do sistema para o compensador ajustado, um segundo ajuste ainda foi realizado no intuito de obter um comportamento mais estável da saída na resposta transitória, o ganho do controlador foi reajustado para " $\mathrm{K}=0.5$ " , a fim de diminuir o sobressinal, contudo, ao diminuir-se o ganho, o sistema fica mais lento, posto isto , o zero do controlador foi reajustado para " $\mathrm{z}=0.92$ " para que um polo mais rápido seja adicionado ao sistema em malha fechada, compensando consequentemente a redução do ganho. A Figura 14 mostra a resposta do compensador reajustado.
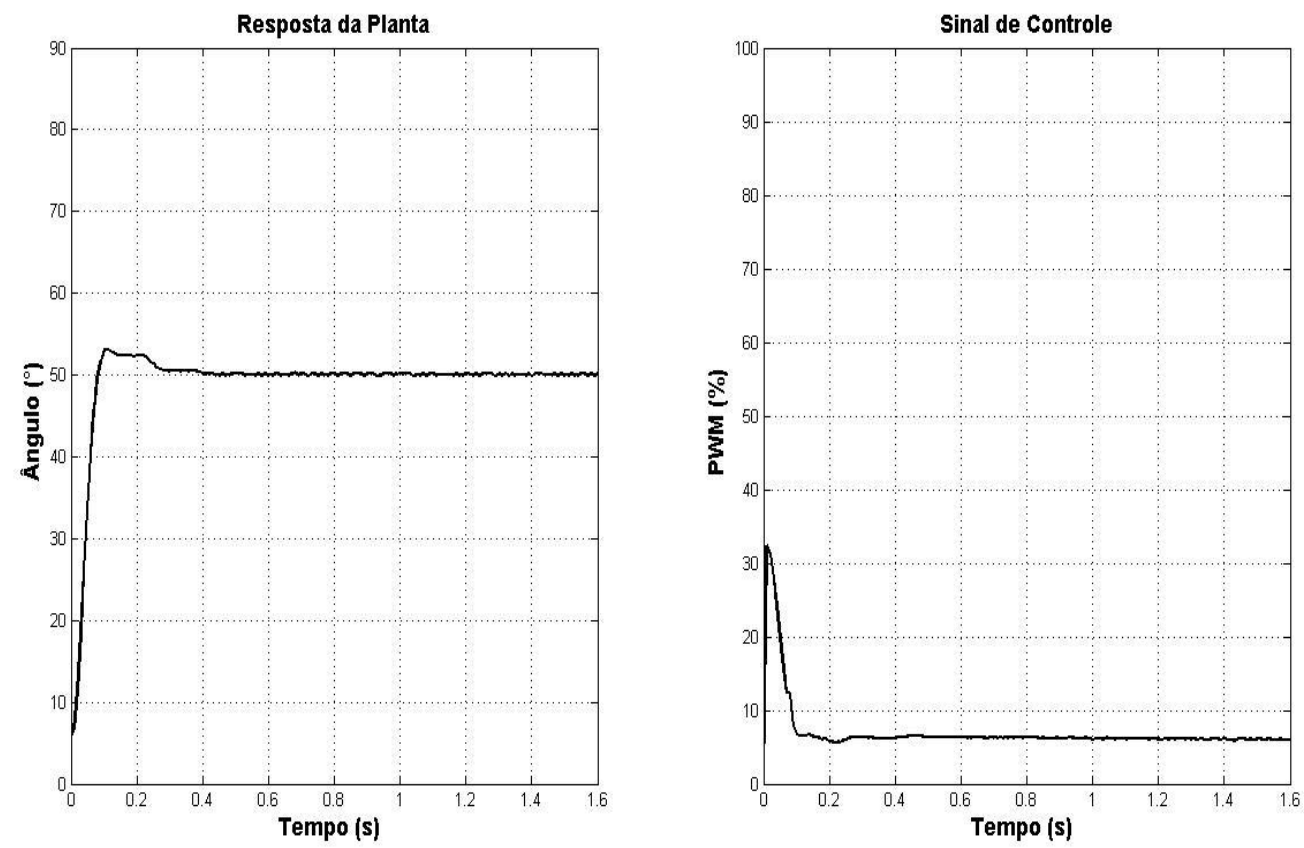

Figura 14- Resposta do sistema para o controlador reajustado

O controlador final é mostrado em (12):

$$
C(z)=0.5 \frac{(z-0.92)}{z-1}
$$

O controlador foi passado para a forma "PID Posicional", para que a parcela integrativa e proporcional ficassem explícitas, conforme as equações a seguir.

$$
\begin{gathered}
u_{I}[n]=u_{I}[n-1]+\frac{K p T s}{2 T_{I}}(e[n]+e[n-1]) \\
u_{P}[n]=K p e[n] \\
u[n]=u_{p}[n]+u_{I}[n]
\end{gathered}
$$


Onde " $u_{I}[n]$ " é a parcela integrativa da enésima iteração, " $u_{P}[n]$ " a parcela proporcional da enésima iteração e " $u_{I}[n-1]$ ” aparcela integrativa da iteração anterior.

A figura 15 ilustra a resposta da planta para uma referência de 60 graus.
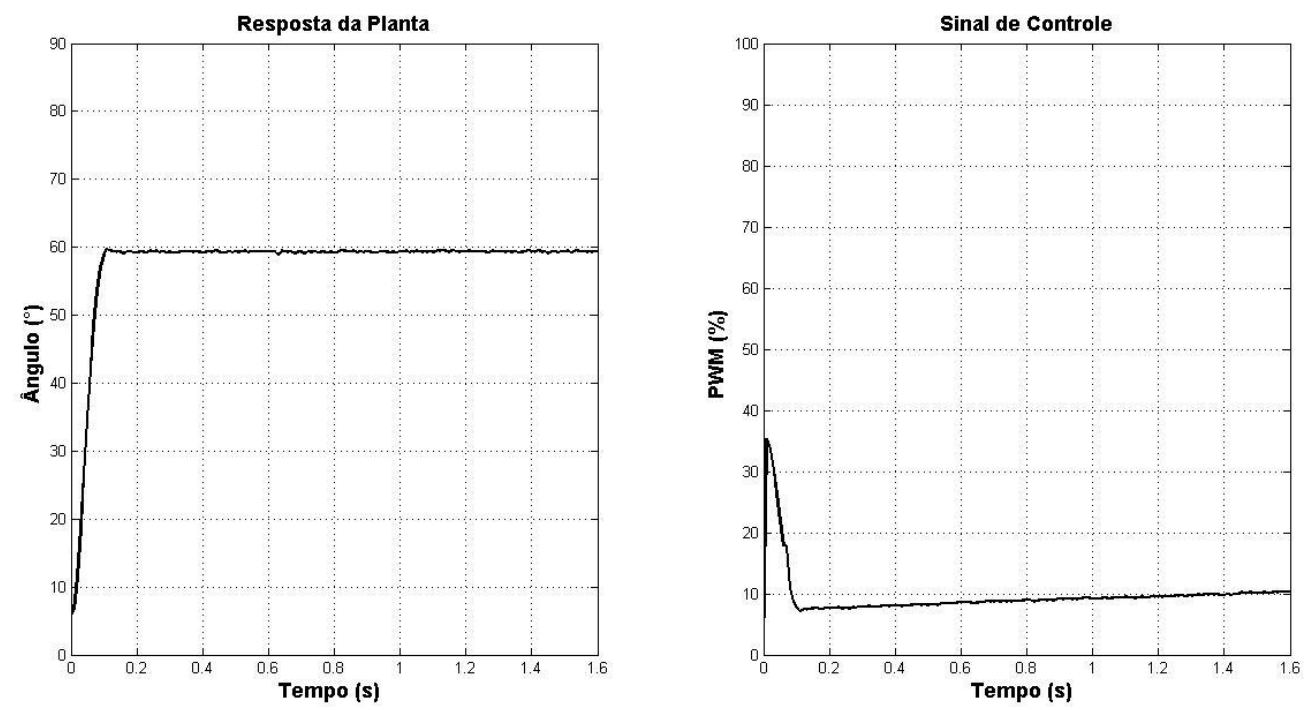

Figura 15- Resposta do sistema para um setpoint de 60 graus.

A Figura 16 ilustra a resposta da planta para uma referência de 45 graus.
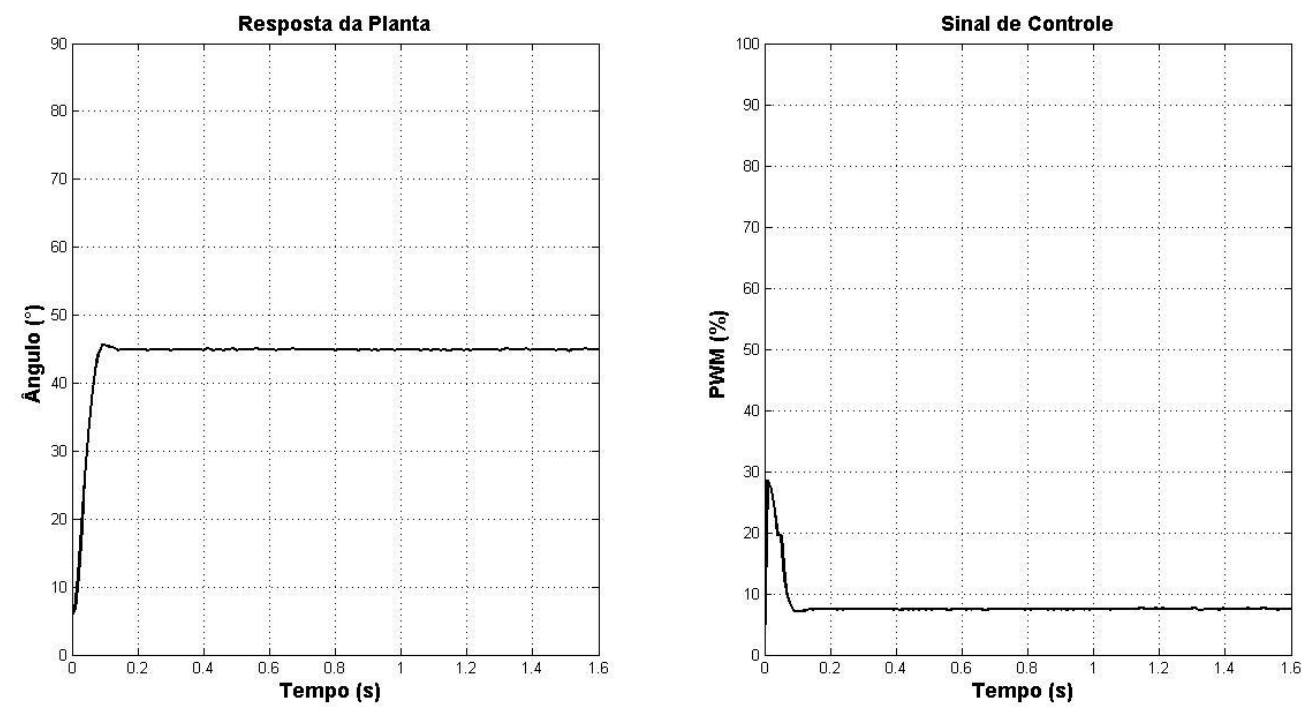

Figura 16- Resposta da planta para um Setpoint de 45 graus.

Como é possível observar, os resultados estão dentro das especificações estabelecidas para a resposta transitória.

A válvula ainda possui a necessidade de ser controlada abaixo da posição limphome, no entanto, o curso do prato desde a posição de repouso até o fechamento completo é 
muito curto, tornando inviável a aquisição para levantamento de um modelo matemático, portanto, optou-se por aplicar ao curso de descida da válvula o próprio controlador obtido para atuar na subida da mesma, realizando-se ajustes empíricos após a implementação para que uma resposta satisfatória fosse obtida pois, a mola que controla a descida da válvula possui características físicas diferentes da mola que controla a subida da mesma.

A figura 17 denota a resposta da planta para uma referência de 3 graus.
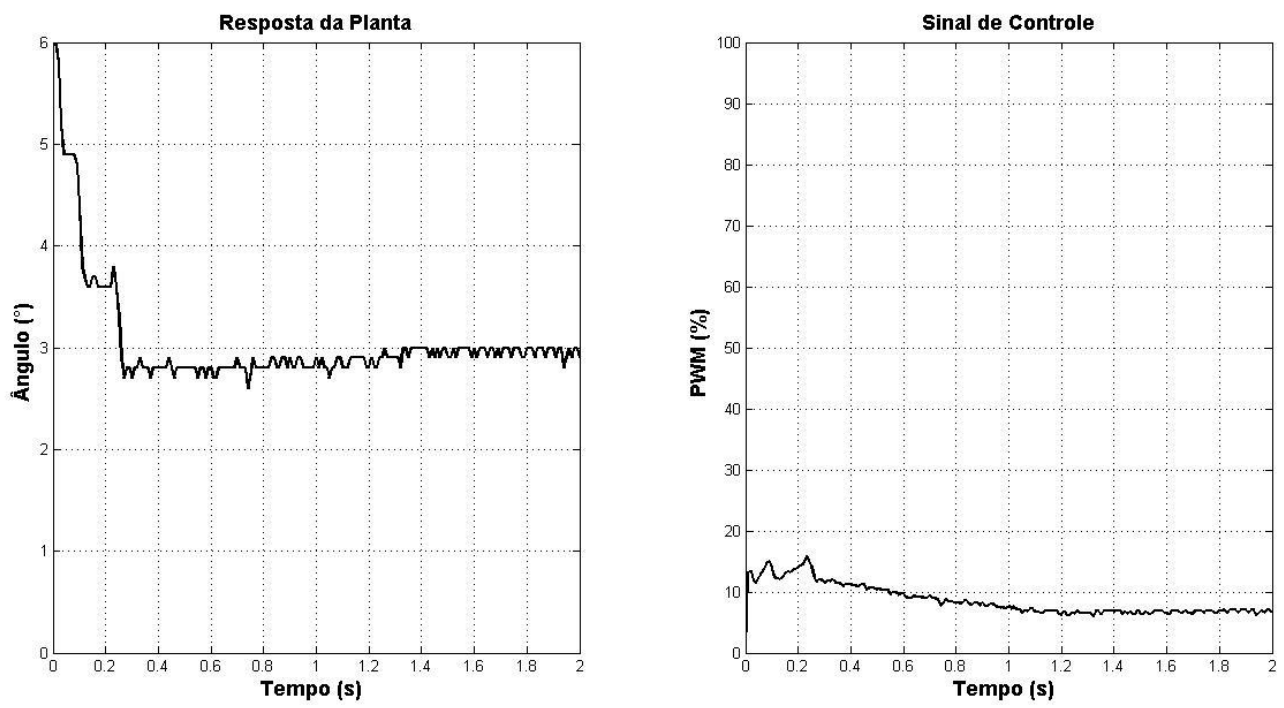

Figura 17- Resposta da planta para um setpoint de 3 graus.

A figura 18 mostra a resposta da planta para uma referência de 2 graus.
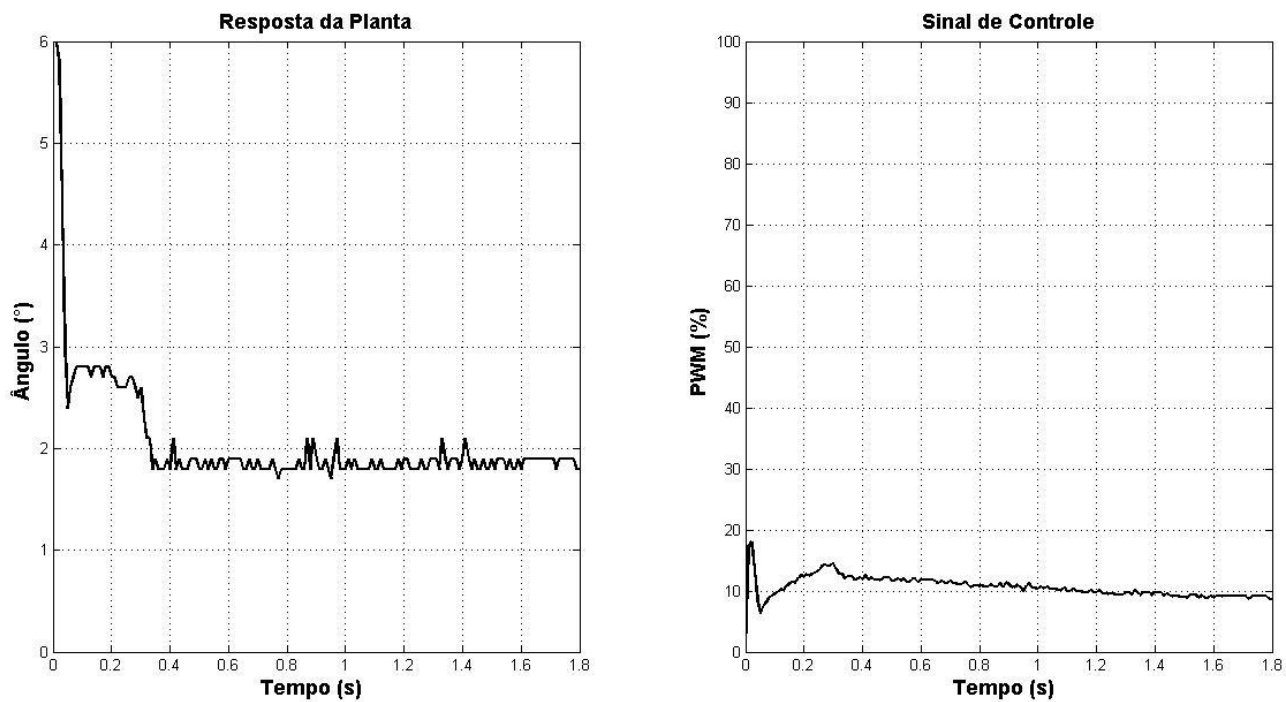

Figura 18- Resposta da planta para um "Setpoint" de 2 graus.

O compensador obtido para controlar a válvula abaixo da posição limphome é:

$$
u_{P}[n]=K p e[n] \Rightarrow K p=3.5 \therefore u_{P}[n]=3.5 e[n]
$$




$$
\begin{gathered}
u_{I}[n]=u_{I}[n-1]+\frac{K p T s}{2 T_{I}}(e[n]+e[n-1]) \Rightarrow T_{I}=10.3 \therefore u_{I}[n-1]+0.18(e[n]+e[n-1]) \\
u[n]=u_{p}[n]+u_{I}[n]
\end{gathered}
$$

O sinal PWM que atua no controle abaixo da posição de repouso tem a sua polaridade invertida se comparado ao sinal que atua no controle de subida, posto isto, a inversão de polaridade do sinal de controle é um evento que ocorrerá ocasionalmente quando se deseja migrar de um estado abaixo da posição limphome para outro estado acima desta posição, ou vice-versa. Contudo, a válvula pode sofrer danos irreversíveis caso o sinal seja invertido e o prato se choque com a força contrária da mola ao passar pela posição de repouso. Para isto, dentro do firmware de controle foi estabelecida uma máquina de estados, onde são levados em conta o ângulo atual da válvula e o valor de setpoint requerido.

A figura 19 ilustra o fluxograma da máquina de estados.

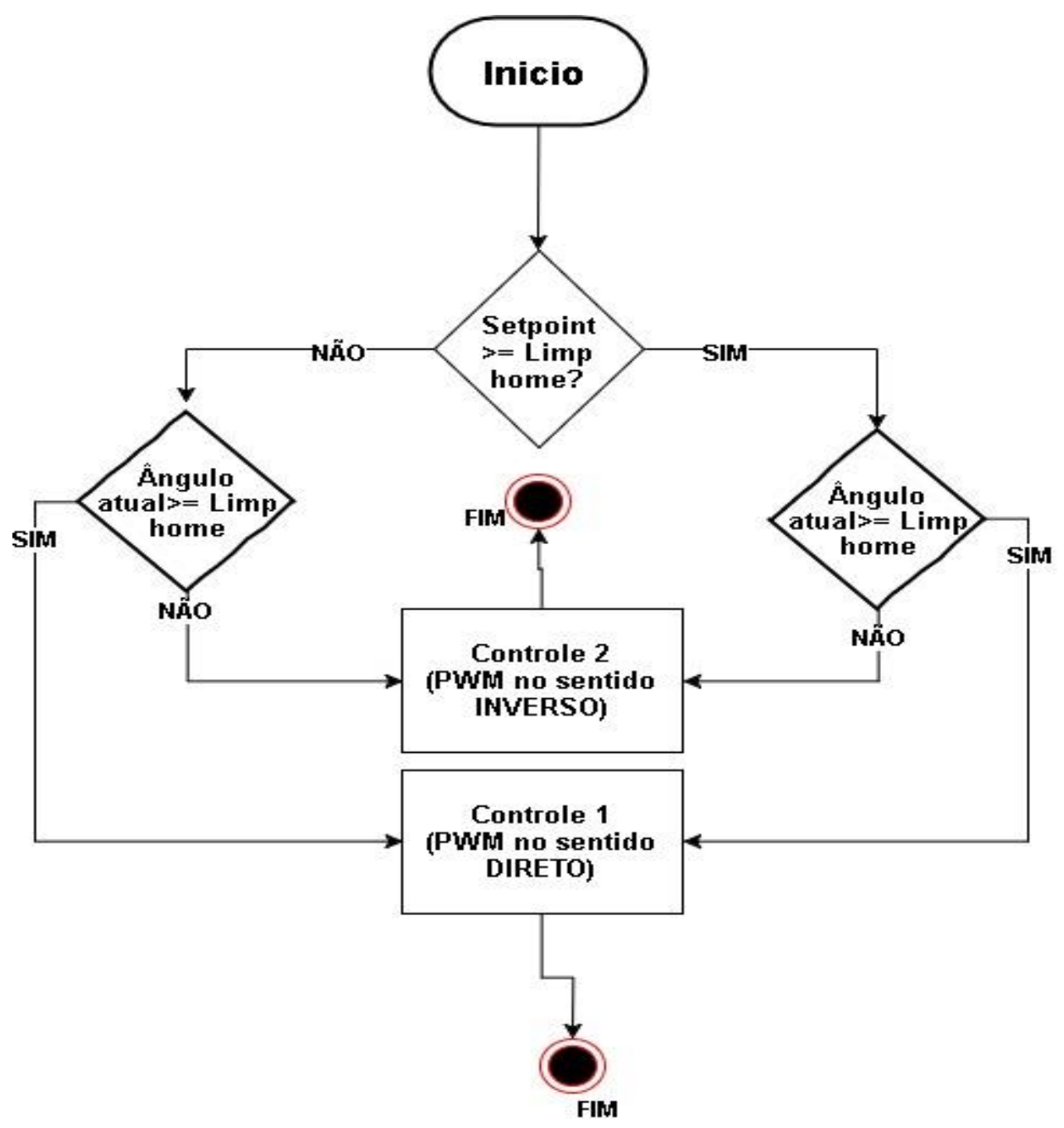

Figura 19- Fluxograma de estados do sistema. 
A partir do fluxograma é possível identificar que o módulo de controle só inverte o PWM quando a válvula passa pela posição de limphome.

Se o setpoint é menor do que a posição limphome e o prato da válvula se encontra em um ângulo acima desta posição, o controlador acionado será o "Controle 1" mostrado em (12) que trabalha com PWM direto. Quando a válvula atingir a posição limphome o controlador utilizado será o "Controle 2" mostrado em (16), (17) e (18) que inverte a polaridade do sinal PWM.

A figura 20 ilustra a situação descrita, onde inicialmente a referência para o controle é de 60 graus, passando posteriormente para 2 graus.
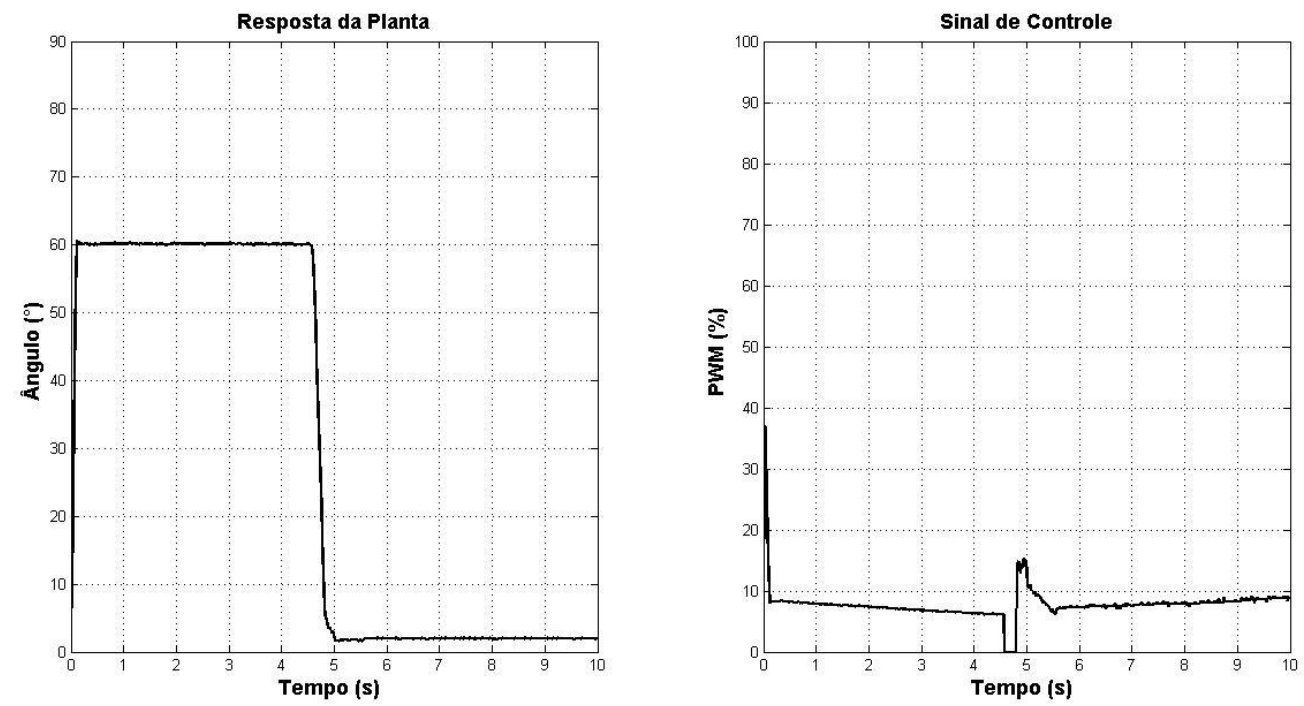

Figura 20- Transição de 60 graus para 2 graus.

\section{CONCLUSÃO}

O controle de posição da válvula borboleta tem grande importância na implementação de uma unidade de controle automotivo. Este projeto teve como proposta o desenvolvimento e aplicação de tal controle em uma válvula borboleta de bancada para ser posteriormente inserido em uma unidade de gerenciamento eletrônico para o veículo "Polo 1.6 Flex" que se encontra em fase de desenvolvimento. Dentre os muitos desafios encontrados, vale destacar as dificuldades em realizar a identificação da planta e ajustar controlador, pois essas etapas não se baseiam simplesmente no desenvolvimento de equações, bem como não se trata de um algoritmo exato ou uma receita que leva ao resultado esperado. A matemática envolvida no projeto do controlador serve para encaminhar o controle para o comportamento almejado, sendo que este, só obtém-se com calibrações feitas a partir de uma análise minuciosa da resposta transitória e do regime estacionário. 
Com os resultados apresentados é categórico afirmar que o controle implementado em um modelo obtido a partir do método de identificação descrito, torna-se completamente viável quando se tem disponibilidade limitada para a obtenção de um modelo físico, uma vez que tal método proporciona resultados extremamente satisfatórios, como proposta de aperfeiçoamento, fica a sugestão de implementar um método para identificação de um modelo que descreva o comportamento da válvula abaixo da posição limphome.

Conclui-se que o projeto traz uma potencial aplicação em um firmware de gerenciamento eletrônico de motores, uma vez que o mesmo propicia soluções para o controle de posição da válvula borboleta. Com os satisfatórios resultados obtidos é possível implementá-lo em um motor real.

\section{REFERÊNCIAS}

[1] AUGUSTO RODRIGUES COELHO, Antônio; DOS SANTOS COELHO, Leandro. Identificação de Sistemas Dinâmicos Lineares. Florianópolis: Editora da UFSC, 2004.

[2] DA SILVA ZANCO, Wagner.Microcontroladores PIC18 com Linguagem C. São Paulo: Érica, 2010.

[3] DE LAURO CASTRUCCI, Plínio; BITTAR, Anselmo; MOURA SALES, Roberto. Controle Automático. Rio de Janeiro: LTC, 2011.

[4] OGATA, Katsuhiko.Engenharia de Controle Moderno. Estados Unidos: PrenticeHall,2002.

[5] REIF, Konrad. Gasoline Engine Management. Friedrichshafen: Springer Vieweg, 2015.

[6] AHMED AL-SAMARRAIE, Shibly; KHUDHAIR ABBAS, Yasir. Design of Eletronic Throttle Valve Position Control System using Nonlinear PID Controller. International Journal of Computer Applications, Iraq-Baghdad, Vol 59, p. 27-34, Dez. 2012.

[7] SILVA PEREIRA, Bruno; FRACISCO JUSTO, João; ANTONIO MARIA LAGANÁ, Armando. Controle da Mistura Ar/Combustível em um Motor a Combustão Interna: Sistema em Malha Fechada. XXIII Simpósio Internacional De Engenharia Automotiva-SIMEA 2015, São Paulo, Vol. 2, p. 1-17, Set. 2015.

[8] THAMIRES DA SILVA, C. Modelamento matemático e controle PI de uma válvula borboleta eletrônica. 2015. 139 p. Dissertação (Mestrado)- Escola Politécnica da Universidade de São Paulo, São Paulo, 22/05/2015. 
[9] MICROCHIP, PIC18F2455/2550/4455/4550 Data Sheet, Ver. E .EUA: 2009. Disponível em: 〈http://ww1.microchip.com/downloads/en/DeviceDoc/39632e.pdf $>$. Acesso em: 02 fev. 2017.

[10]NXP , H-Bridge Driver, Ver. 8. EUA: 2013. Disponível em:

<http://www.nxp.com/assets/documents/data/en/data-sheets/MC33186.pdf> Acesso em: 01 jan. 2017.

[11]EBAH. Pwm microcontrolador 8051. Disponível em: <http://www.ebah.com.br.>. Acesso em: 01 jan. 2017. 